\title{
INFLUENCE DE LA CASTRATION TARDIVE DU PORC MALE SUR LA QUaLITÉ Des CARCASSES ET L'UTILISATION DE LA VIANDE
}

\author{
C. TEXIER, B. DFSMOULIN et L. DUMONT \\ Institut technique du Porc, 60, rue Caumartin, $75-$ Paris $8 \mathrm{e}$
}

\section{RÉSUMÉ}

Quatre-vingt-quatre porcs mâles d'un poids initial de $24 \pm 2 \mathrm{~kg}$ ont été affectés à 4 traitements :

a) castrés à $25 \mathrm{~kg}, b$ ) castrés à $70 \mathrm{~kg}, c$ ) castrés à $90 \mathrm{~kg}, d$ ) non castrés. La castration était effectuce par ablation des testicules et des tissus annexes. L'aliment granulé renfermant 16 p. Ioo de matière azotée et $3800 \mathrm{kcal} / \mathrm{kg}$ de matière sèche, était distribué ad libitum aux porcs répartis selon le traitement en loges collectives. L'abattage avait lieu à $102 \pm 2 \mathrm{~kg}$. Sur l'ensemble de la période d'engraissement (de 24 à IO2 $\mathrm{kg}$ ), les gains de poids de tous les animaux étaient comparables ( $6 \mathrm{I}_{4} \mathrm{~g} / \mathrm{jour}$ en moyenne) ; en revanche, les indices de consommation étaient respectivement pour les traitements $a, b, c, d=4,5,4,3,4, \mathrm{o}$ et $4, \mathrm{o}$. La castration tardive à $90 \mathrm{~kg}$ et la non-castration permettent donc un gain de Io p. Ioo sur l'efficacité alimentaire ; elles améliorent nettement la qualité des carcasses et permettent un gain de Io à 15 p. Ioo sur la proportion de morceaux maigres des carcasses. L'examen organoleptique a révélé l'apparition de l'ođeur sexuelle chez 44 p. Ioo des mâles non castrés, majs aussi chez 22 p. Ioo des mâles castrés à $25,7^{\circ}$ ou $90 \mathrm{~kg}$. Des études complémentaires sur l'endocrinologie de l'engraissement sont encore nécessaires.

\section{SUMMARY}

LATE CASTRATION OF THE MALE PIG : EFFECT ON CARCASS QUALITY AND MEAT UTILIZATION

Eighty- four male pigs, initially weighing $24 \pm 2 \mathrm{~kg}$, were divided into 4 groups :

a) castrated at $25 \mathrm{~kg}, b$ ) castrated at $70 \mathrm{~kg}, c$ ) castrated at $90 \mathrm{~kg}, d$ ) uncastrated. Castration was performed by removal of the testes and accessory tissues. A pellet ration containing $16 \mathrm{p}$. Ioo crude protein and $3800 \mathrm{kcal} / \mathrm{kg}$ of dry matter, were fed ad libitum to the pigs which were confined to group-pens, according to experimental group. The daily weight gain for the whole fattening 
period $\left(24\right.$ to $102 \mathrm{~kg}$ ) was nearly the same for all animals (about $6 \mathrm{I}_{4} \mathrm{~g} /$ day), but Feed/gain ratio for the different groups $a, b, c, d$, were $4.5,4.3,4.0$ and 4.0 respectively. Late castration at $90 \mathrm{~kg}$ and no castration caused a Io p. Ioo gain of feed efficiency. Carcass quality was improved and there was a 1o-r 5 p. Ioo gain on the proportion of lean cuts. Organoleptic examination showed a sexual odor in $44 \mathrm{p}$. Ioo of uncastrated males, but $22 \mathrm{p}$. Ioo of males castrated at 25,70 or $90 \mathrm{~kg}$ also showed this odor. Additional studies on fattening endocrinology are necessary.

GÉNÉTIQUE

\title{
L'UTILISATION DES INDICES DE SÉLECTION DANS L'AMÉLIORATION DU PORC.
}

\author{
L. OLLIVIER \\ Laboratoive de Génétique quantitative et appliquée, \\ Centre national de Recherches zootechniques, 78 -Jouy-en-Josas \\ Institut national de la Recherche agronomique
}

\section{RÉSUMÉ}

Cet article expose la démarche suivie pour établir des indices de sélection basés sur des mesures concernant soit le verrat lui-même (contrôle individuel), soit huit de ses descendants, à raison de 4 groupes de 2 (contrôle de descendance), soit le verrat lui-même et deux frères de portée (contrôle combiné). Les calculs utilisent des valeurs relatives de chaque critère estimées dans les conditions économiques de l'élevage du porc en France en 1969 et les paramètres statistiques et génétiques du porc Large White Français. Les trois méthodes de sélection considérées sont très voisines en efficacité. La première méthode, basée sur le contrôle individuel des verrats, est donc à recommander, vu son faible coût, dans les conditions économiques actuelles, si on veut améliorer rapidement la rentabilité de l'engraissement du porc en France. On peut, en effet, estimer à $7 \mathrm{~F}$ par porc engraissé le bénéfice qu'apporte par génération cette méthode de sélection, si on garde pour la reproduction les 20 p. Ioo supérieurs des verrats mis en contrôle.

\section{SUMMARY}

\section{USE OF SELECTION INDEXES IN PIG IMPROVEMENT}

This articles discusses the method of establishing selection indexes based on measures concerning either the boar itself (individual testing) or eight of his descendants in 4 groups of 2 (progeny testing), or the boar itself and two brothers of the litter (combined testing). The three selec- 